\title{
Surgical outcomes of acute type A aortic dissection in patients undergoing cardiopulmonary resuscitation
}

Kyokun Uehara, MD, PhD, Hitoshi Matsuda, MD, PhD, Jiro Matsuo, MD, Yosuke Inoue, MD, Takayuki Shijo, MD, Atsushi Omura, MD, PhD, Yoshimasa Seike, MD, Hiroaki Sasaki, MD, PhD, and Junjiro Kobayashi, MD, PhD

\section{ABSTRACT}

Objectives: The surgical indications for acute type A aortic dissection (AAAD) in patients in cardiopulmonary arrest remain controversial. Outcomes of AAAD for patients who underwent cardiopulmonary resuscitation (CPR) were evaluated.

Methods: Between 2004 and 2018, of the 519 patients who underwent AAAD repair, $34(6.6 \%)$ required CPR before or on starting AAAD repair. The patients were divided into 2 groups, survivors $(n=13)$ and nonsurvivors $(n=21)$, to compare the early operative outcomes, including mortality and neurological events.

Results: The major cause of cardiovascular collapse requiring CPR was aortic rupture/cardiac tamponade $(n=21[61.8 \%])$, followed by coronary malperfusion $(n=12[35.3 \%])$ and acute aortic valve regurgitation $(n=3[8.8 \%])$. There were $3(23.1 \%)$ patients in the survivors group and $11(52.4 \%)$ in the nonsurvivors group who required ongoing CPR at the beginning of AAAD repair $(P=.039)$. Of these patients, 1 survivor and 6 nonsurvivors could not achieve return of spontaneous circulation after pericardiotomy $(P=.045)$. Although the duration from onset or arrival to the operating room was similar $(P=.35$ and $P=.49$, respectively), overall duration of CPR was shorter in survivors (10 minutes [range, $7.5-16 \mathrm{mi}$ nutes] vs 16.5 minutes [range, $15-20$ minutes]; $P=.044$ ). All survivors without any neurological deficits showed return of spontaneous circulation after pericardiotomy. Multivariate regression modeling showed that CPR duration $>15$ minutes was a significant risk factor for in-hospital mortality $(P=.0040)$.

Conclusions: CPR duration beyond 15 minutes may be a contraindication for AAAD repair. Moreover, we should reconsider surgery for patients who cannot achieve return of spontaneous circulation after pericardiotomy. ( $J$ Thorac Cardiovasc Surg 2021;161:1173-80)

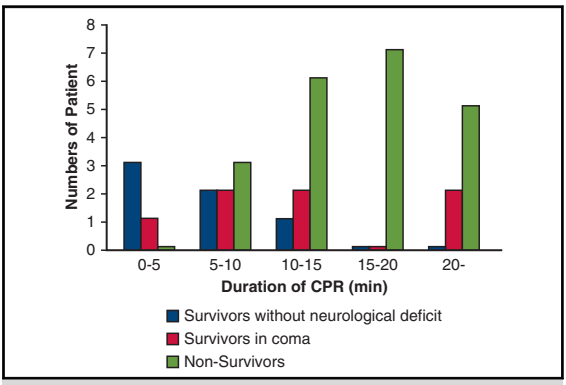

Outcomes of AAAD repair after CPR by duration of CPR.

\section{CENTRAL MESSAGE}

CPR duration exceeding 15 minutes may be a contraindication for AAAD repair in patients undergoing CPR before surgery.

\section{PERSPECTIVE}

In addition to CPR before surgery being known to be among the significant risk factors for in-hospital mortality after AAAD repair, CPR duration exceeding 15 minutes may be a contraindication for AAAD repair in patients undergoing CPR before surgery. Further analysis should clarify definitive surgical guidelines for serious-status patients who could not achieve ROSC even after pericardiotomy.

See Commentaries on pages 1181 and 1182.
From the Department of Cardiovascular Surgery, National Cerebral and Cardiovascular Center, Suita, Osaka, Japan.

Disclosures: Authors have nothing to disclose with regard to commercial support.

Read at the 99th Annual Meeting of The American Association for Thoracic Surgery, Toronto, Ontario, Canada, May 4-7, 2019.

Received for publication Aug 2, 2019; revisions received Nov 24, 2019; accepted for publication Nov 27, 2019; available ahead of print Jan 7, 2020.

Address for reprints: Hitoshi Matsuda, MD, PhD, Department of Cardiovascular Surgery, National Cerebral and Cardiovascular Center, 6-1 Kishibe-shinmachi, Suita, 564-8565, Osaka, Japan (E-mail: hitmat@mist.ocn.ne.jp).

$0022-5223 / \$ 36.00$

Copyright $\odot 2020$ by The American Association for Thoracic Surgery

https://doi.org/10.1016/j.jtcvs.2019.11.135
Acute type A aortic dissection (AAAD) is still a challenging disease, and prompt surgery is recommended to prevent fatal complications, including rupture. ${ }^{1-3}$ Cardiopulmonary resuscitation (CPR) before surgery

Scanning this $\mathrm{QR}$ code will take you to the table of contents to access supplementary information. To view the AATS Annual Meeting Webcast, see the URL next to the webcast thumbnail.

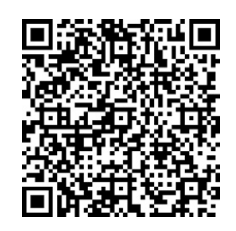




\section{Abbreviations and Acronyms \\ $\mathrm{AAAD}=$ acute type $\mathrm{A}$ aortic dissection \\ $\mathrm{ACP}=$ antegrade cerebral perfusion \\ $\mathrm{CPR}=$ cardiopulmonary resuscitation \\ $\mathrm{ECMO}=$ extracorporeal membrane oxygenation \\ IABP $=$ intra-aortic balloon pump \\ IHCA $=$ in-hospital cardiac arrest \\ OHCA $=$ out-of-hospital cardiac arrest \\ ROSC $=$ return of spontaneous circulation}

\section{Statistical Analysis}

Data were collected from hospital admission and outpatient medical records. All patients were followed as outpatients either at our hospital or by a local physician. Values are presented as median (interquartile range, 25th and 75 th percentiles) for continuous variables and $\mathrm{n}(\%)$ for categorical variables. Categorical variables were evaluated using Fisher exact analysis, whereas continuous variables were analyzed using $t$ test or the MannWhitney U test. A Cox proportional hazards regression model was used for the multivariable analysis of in-hospital mortality. Statistical analyses were conducted using SPSS software (IBM-SPSS Inc, Armonk, NY). This retrospective observational study was approved by our institutional review board (M30-057) and individual oral and written informed consent was waived for the retrospective use of patients' data.

\section{RESULTS}

The characteristics of all patients are summarized in Table 1 . There were 13 survivors $(38.2 \%)$ and 21 nonsurvivors $(61.8 \%)$. Survivors tended to be older, although the difference was not significant $(P=.093)$. More than half of the patients were men, and the majority had DeBakey type I aortic dissection. Two patients required multiple CPR before AAAD repair. One patient underwent CPR at the primary hospital and then experienced cardiac arrest in the ambulance on the way to our hospital, when CPR was again required. The other patient underwent CPR with pericardial drainage at the primary hospital, and the secondary CPR was initiated at the emergency room after arrival at our hospital. This patient's OHCA and IHCA overlapped; therefore, each duration of CPR was added to analyze the total duration of CPR. OHCA or IHCA did not show a significant difference in in-hospital mortality ( $P=.72$ and $P=.53$, respectively).

The major reason for cardiovascular collapse requiring CPR was aortic rupture and/or cardiac tamponade in 21 patients $(61.8 \%)$. Coronary malperfusion was identified in 12 patients $(35.3 \%)$. Acute congestive heart failure following severe aortic regurgitation was found in 3 patients $(8.8 \%)$. Patients with many of these reasons were counted for each reason. More nonsurvivors showed coronary malperfusion $(38.1 \%)$, but there was no significant difference $(P=.17)$.

There were 4 patients $(11.8 \%$ ) with preoperative ECMO support. Three patients with coronary malperfusion were transferred to our hospital under ECMO support that was started from peripheral vessels at the primary hospital. One patient, who was transported directly to our hospital with ST elevation on electrocardiogram, was rushed to the catheter laboratory, and ECMO was initiated because of cardiac arrest. During the coronary angiogram, AAAD was first detected, and only this patient underwent successful coronary angioplasty with a stent in the left main trunk before AAAD repair and survived the operation.

Blood gas values for all 34 patients showed severe acidosis with a median $\mathrm{pH}$ of 7.29 , base excess of $-6.8 \mathrm{mmol} / \mathrm{L}$, and a lactate level of $10.1 \mathrm{mmol} / \mathrm{dL}$. The level 
TABLE 1. Preoperative characteristics

\begin{tabular}{|c|c|c|c|c|}
\hline Characteristic & $\begin{array}{c}\text { Overall } \\
(N=34)\end{array}$ & Survivors $(n=13)$ & $\begin{array}{l}\text { Nonsurvivors } \\
\qquad(\mathbf{n}=\mathbf{2 1})\end{array}$ & $P$ value \\
\hline Age (y) & $69(59,78)$ & $71(65,79)$ & $66(58,77)$ & .093 \\
\hline Male gender & $19(55.9)$ & $8(61.5)$ & $11(52.4)$ & .31 \\
\hline DeBakey type I & $29(85.3)$ & $11(84.6)$ & $18(85.7)$ & .34 \\
\hline DeBakey type II & $2(5.9)$ & $1(7.7)$ & $1(4.8)$ & .17 \\
\hline DeBakey type III & $3(8.8)$ & $1(7.7)$ & $2(9.5)$ & .34 \\
\hline OHCA & $17(50.0)$ & $7(53.8)$ & $10(47.6)$ & .72 \\
\hline IHCA & $18(52.9)$ & $6(46.2)$ & $12(57.1)$ & .53 \\
\hline \multicolumn{5}{|l|}{ Reasons for CPR } \\
\hline Aortic rupture or cardiac tamponade & $21(61.8)$ & $9(69.2)$ & $12(57.1)$ & .17 \\
\hline Coronary malperfusion & $12(35.3)$ & $3(23.1)$ & $8(38.1)$ & .17 \\
\hline Aortic valve regurgitation & $3(8.8)$ & $1(7.7)$ & $1(4.8)$ & .18 \\
\hline Pericardial drainage & $1(2.9)$ & 0 & $1(4.8)$ & .16 \\
\hline ECMO support & $4(11.8)$ & $1(7.7)$ & $3(14.3)$ & .31 \\
\hline \multicolumn{5}{|l|}{ Blood gas data at arrival } \\
\hline $\mathrm{PH}$ & $7.29(7.13,7.34)$ & $7.34(7.20,7.35)$ & $7.27(7.14,7.34)$ & .18 \\
\hline Base excess (mEq/L) & $-6.8(-12.4,-2.7)$ & $-3.8(-9.6,0.057)$ & $-10.1(-13.0,-4.52)$ & .089 \\
\hline Lactate (mmol/dL) & $10.1(4.1,12.4)$ & $4.2(3.7,11.7)$ & $10.4(8.3,13.6)$ & .17 \\
\hline Onset to operating theatre $(\mathrm{h})$ & $3.5(2.1,5.0)$ & $2.5(1.0,6.4)$ & $3.5(2.4,4.6)$ & .35 \\
\hline Arrival to operating theatre (min) & $24(10,35)$ & $25(11,37)$ & $22(9.5,33.5)$ & .49 \\
\hline Duration of CPR (min) & $15(10,20)$ & $10(7.5,16)$ & $16.5(15,20)$ & .044 \\
\hline
\end{tabular}

Values are presented as median $(25 \%, 75 \%)$ for continuous variables or n $(\%)$ for categorical variables. $O H C A$, Out-of-hospital cardiac arrest; $I H C A$, in-hospital cardiac arrest; $C P R$, cardiopulmonary resuscitation; $E C M O$, extracorporeal membrane oxygenation; $P H$, potential of hydrogen.

of acidosis was more severe in nonsurvivors, but there was no significant difference. The median interval from onset to the operating room was 2.5 hours (range, 1.0-6.4 hours) in survivors and 3.5 hours (range, 2.4-4.6 hours) in nonsurvivors $(P=.35)$, and the time from arrival to the operating room was 25 minutes (range, 11-37 minutes) and 22 minutes (range, 9.5-33.5 minutes), respectively $(P=.49)$. The overall median duration of CPR was 15 minutes, and the survivors showed shorter duration of CPR, 10 minutes (range, 7.5-16 minutes) compared with nonsurvivors, 16.5 minutes (range, 15-20 minutes) $(P=.044)$.

Figure 1 shows the chart of ROSC. Eight patients underwent CPR at the primary hospital, and 3 of those 8 patients were transferred with ECMO support. Three of 9 patients who underwent CPR at home or in an ambulance did not achieve ROSC and were rushed to the operating room under ongoing CPR. In patients with IHCA, 6 of the 12 patients who underwent $\mathrm{CPR}$ in the emergency room achieved ROSC, including 1 patient with ECMO. In 5 of 6 patients who underwent $\mathrm{CPR}$ in the operating room, AAAD repair was started with ongoing CPR. Overall, 14 of 34 patients $(41.2 \%)$ underwent emergency AAAD repair with ongoing CPR.

The perioperative results are summarized in Table 2. Even after pericardiotomy, ROSC was not achieved in 7 of 14 patients $(50 \%)$ with ongoing CPR at the beginning of surgery. More patients in the nonsurvivors group could not achieve ROSC after pericardiotomy $(7.7 \%$ vs $28.6 \%$; $P=.045)$. In AAAD repair, more patients underwent hemi- or partial arch replacement than total arch replacement, but total arch replacement did not increase nonsurvivors $(P=.19)$. Concomitant procedures included aortic root surgery with a modified Bentall operation in 3 patients $(8.8 \%)$, and coronary artery bypass grafting in 3 patients $(8.8 \%)$. Although there were no significant differences in operative procedures and concomitant procedures between the survivors and nonsurvivors, nonsurvivors frequently required mechanical support after AAAD repair. One survivor $(7.7 \%)$ and 8 nonsurvivors $(38.1 \%)(P=.004)$ required intra-aortic balloon pump (IABP) support. ECMO support was started in 1 survivor $(7.7 \%)$ and 10 nonsurvivors $(47.6 \%)(P<.001)$. The 1 survivor was supported with ECMO before AAAD repair because of occlusion of the left main trunk described above. Nonsurvivors included the 3 patients with preoperative ECMO support due to OHCA who could not be weaned from cardiopulmonary bypass and required ECMO support again. Of 14 patients with ongoing CPR at the beginning of AAAD repair, 3 survived the operation and 11 died $(P=.039)$. The 2 patients experiencing multiple CPR events died after AAAD repair. 


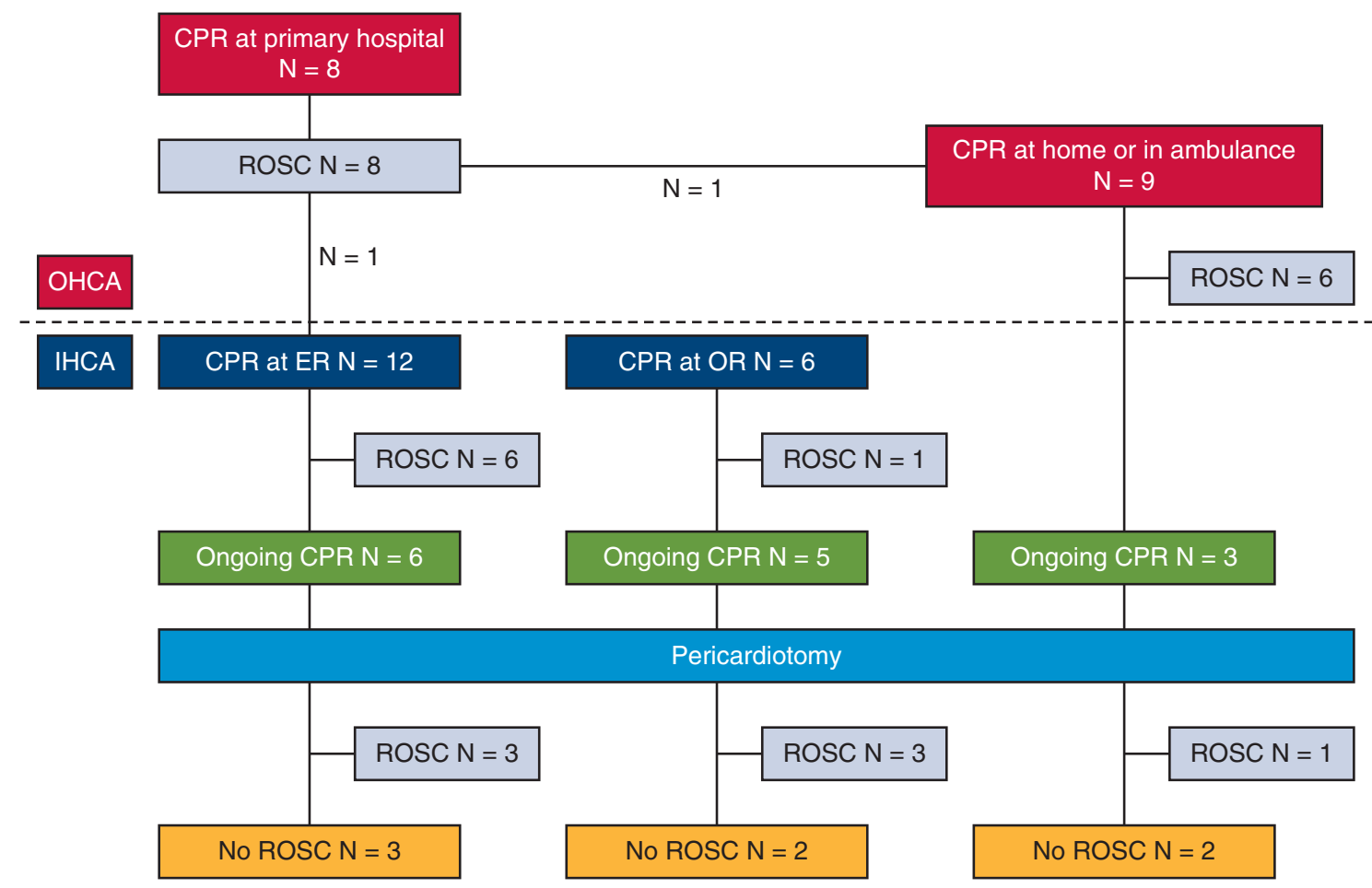

FIGURE 1. Flowcharts of return of spontaneous circulation $(R O S C)$ in patients undergoing cardiopulmonary resuscitation $(C P R)$. Eight patients underwent $\mathrm{CPR}$ at the primary hospital, and 2 of those 8 patients required multiple CPR in the ambulance or at an emergency room $(E R)$. Three of 9 patients who underwent CPR at home or in an ambulance did not achieve ROSC and were rushed to the operating room under ongoing CPR. Six of 12 patients who underwent $\mathrm{CPR}$ in an ER achieved ROSC, including 1 patient who underwent extracorporeal membrane oxygenation (ECMO). In 5 of 6 patients who underwent CPR in the operating room, acute type A aortic dissection (AAAD) repair was started with ongoing CPR. Overall, 14 of 34 patients underwent emergency AAAD repair with ongoing CPR. Of those 14 patients, 7 patients could not achieve ROSC after pericardiotomy. OHCA, Out-of-hospital cardiac arrest; IHCA, in-hospital cardiac arrest; $O R$, operating room.

Operation time, myocardial ischemic time, circulatory arrest time, and ACP time showed no significant differences ( $P$ values $=.31, .23, .12$, and .35 , respectively $)$, but the duration of cardiopulmonary bypass was shorter: 240 minutes (193, 288 minutes), in the survivors compared with nonsurvivors, 366 minutes (240, 461 minutes) $(P=.016)$.

After AAAD repair, 6 patients (18\%) could walk unaided without any neurological deficit (Table 3). Two of these 6 patients had undergone AAAD repair with ongoing CPR, and ROSC was achieved after pericardiotomy. These patients were transferred to the rehabilitation hospital without any neurological complications. However, the remaining 7 survivors were all comatose due to severe hypoxic encephalopathy and were transferred to a nursing home. The mean duration of CPR was shorter, but without a significant difference, in patients who survived without a neurological deficit than patients who survived and remained in a coma $(8.7 \pm 5.8$ minutes and $16.0 \pm 11.8$ minutes, respectively; $P=.089)$. ROSC had been obtained within 10 minutes in 5 of 6 patients. Figure 2 summarizes the survivors without neurological deficits or in coma and the nonsurvivors in relation to the duration of CPR. There was no survivor without any neurological complications among patients experiencing CPR exceeding 15 minutes. The univariable analysis showed that the significant risk factors for inhospital mortality were CPR duration exceeding 15 minutes, ongoing CPR at the beginning of surgery, and no ROSC after pericardiotomy (Table 4). The multivariable analysis showed that CPR duration of more than 15 minutes was the strongest predictor of in-hospital mortality (hazard ratio, $8.27 ; 95 \%$ confidence interval, $1.33-32.4 ; P=.004$ ).

\section{DISCUSSION}

AAAD is a serious and life-threatening aortic emergency that can result in sudden death. The latest report from the International Registry of Acute Aortic Dissection stated that the in-hospital mortality rate remains high, at $22 \%$. Like other studies demonstrating improved surgical results of AAAD, ${ }^{10-13}$ Japanese registry data have shown an improved 30-day mortality after AAAD repair, which was $17.4 \%$ in 2001 and $12.1 \%$ in $2015 .{ }^{14}$ 
TABLE 2. Perioperative details

\begin{tabular}{|c|c|c|c|c|}
\hline Characteristic & Overall $(\mathbf{N}=\mathbf{3 4})$ & Survivors $(n=13)$ & Nonsurvivors $(n=21)$ & $P$ value \\
\hline Ongoing CPR at the beginning of surgery & $14(41.2)$ & $3(23.1)$ & $11(52.4)$ & .039 \\
\hline No ROSC after pericardiotomy & $7(20.6)$ & $1(7.7)$ & $6(28.6)$ & .045 \\
\hline Hemi- or partial arch replacement & $21(61.8)$ & $8(61.5)$ & $13(61.9)$ & .49 \\
\hline Total arch replacement & $13(38.2)$ & $5(38.5)$ & $8(38.1)$ & .19 \\
\hline \multicolumn{5}{|l|}{ Concomitant procedure } \\
\hline Aortic root replacement & $3(8.8)$ & $1(7.7)$ & $2(9.5)$ & .44 \\
\hline CABG & $3(8.8)$ & $1(7.7)$ & $2(9.5)$ & .44 \\
\hline IABP & $9(26.5)$ & $1(7.7)$ & $8(38.1)$ & .004 \\
\hline ECMO & $11(32.4)$ & $1(7.7)$ & $10(47.6)$ & $<.001$ \\
\hline Operation time (min) & $536(460,731)$ & $508(415,548)$ & $565(471,770)$ & .31 \\
\hline $\mathrm{CPB}(\min )$ & $294(219,436)$ & $240(193,288)$ & $366(240,461)$ & .016 \\
\hline Myocardial ischemia (min) & $145(101,174)$ & $105(99,154)$ & $154(106,195)$ & .23 \\
\hline Circulatory arrest (min) & $54(40,74)$ & $48(39,59)$ & $63(42,91)$ & .12 \\
\hline $\mathrm{ACP}(\min )$ & $118(43,174)$ & $54(44,167)$ & $127(43,174)$ & .35 \\
\hline
\end{tabular}

Values are presented as median $(25 \%, 75 \%)$ for continuous variables or $\mathrm{n}(\%)$ for categorical variables. $C P R$, Cardiopulmonary resuscitation; $R O S C$, return of spontaneous circulation; $C A B G$, coronary artery bypass grafting; $I A B P$, intra-aortic balloon pump; $E C M O$, extracorporeal membrane oxygenation; $C P B$, cardiopulmonary bypass; $A C P$, antegrade cerebral perfusion.

Because no other life-saving options are available for AAAD after or during CPR, decisions about discontinuation of life-saving processes are usually critical and difficult after huge prehospital efforts in the chain to save life and in consideration also of the wishes of patients and their families. Certainly, we should not be overly distracted by a few successes; instead we should make objective decisions.

In this report of our experiences over about 15 years under the policy "to perform surgery even in patients with extremely low probability of survival," we intended to explore those factors that would justify discontinuing treatment in a patient with AAAD after or during CPR. Our facility specializes in cardiovascular diseases, and a dedicated multidisciplinary aortic team is available to start emergency surgery usually within half an hour after arrival. When patients undergoing CPR were referred for treatment, the aortic team had usually prepared the operating room to receive the patient directly from the ambulance. In fact,

TABLE 3. Details of the survivors

\begin{tabular}{|c|c|c|c|c|c|c|c|c|}
\hline Patient & Age (y) & Gender & Discharge to & $\begin{array}{c}\text { Neurological } \\
\text { deficit }\end{array}$ & $\begin{array}{c}\text { Reason } \\
\text { for CPR }\end{array}$ & At sternotomy & $\begin{array}{c}\text { After } \\
\text { pericardiotomy }\end{array}$ & $\begin{array}{l}\text { Duration of } \\
\text { CPR (min) }\end{array}$ \\
\hline 1 & 66 & Male & Home & - & Coronary & ROSC & - & 3 \\
\hline 2 & 57 & Male & Home & - & Coronary & ROSC & - & 5 \\
\hline 3 & 55 & Male & Home & - & Rupture & ROSC & - & 10 \\
\hline 4 & 65 & Male & Home & - & Coronary & ROSC & - & 19 \\
\hline 5 & 83 & Male & Rehabilitation hospital & - & Rupture & Ongoing CPR & ROSC & 10 \\
\hline 6 & 72 & Male & Rehabilitation hospital & - & Rupture & Ongoing CPR & ROSC & 5 \\
\hline 7 & 72 & Male & Nursing home & Coma & Tamponade & ROSC & - & 8 \\
\hline 8 & 71 & Male & Nursing home & Coma & Tamponade & ROSC & - & 12 \\
\hline 9 & 65 & Female & Nursing home & Coma & Rupture & ROSC & - & 26 \\
\hline 10 & 79 & Female & Nursing home & Coma & Coronary & ROSC & - & 13 \\
\hline 11 & 80 & Female & Nursing home & Coma & Rupture & Ongoing CPR & ROSC & 5 \\
\hline 12 & 81 & Female & Nursing home & Coma & Rupture & ROSC & - & 38 \\
\hline 13 & 70 & Male & Nursing home & Coma & Rupture & Ongoing CPR & Arrest & 10 \\
\hline
\end{tabular}

$C P R$, Cardiopulmonary resuscitation; $R O S C$, return of spontaneous circulation. 


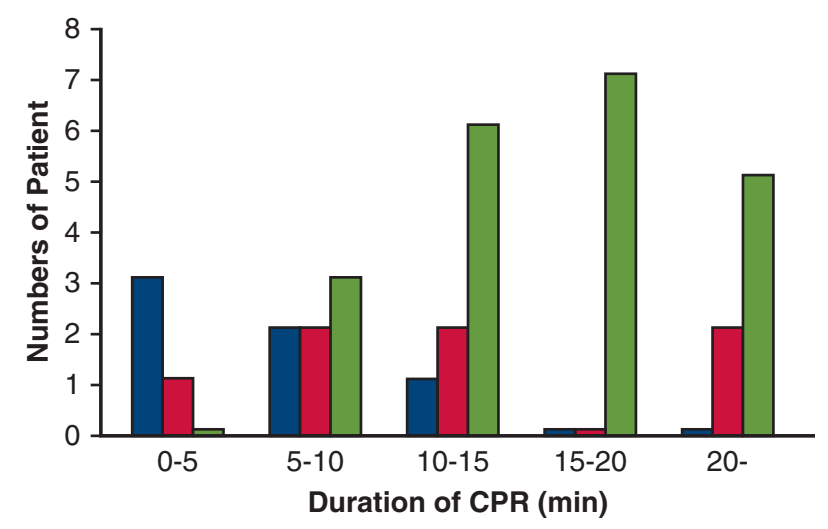

Survivors without neurological deficit

Survivors in coma

$\square$ Non-Survivors

FIGURE 2. Outcomes of acute type A aortic dissection (AAAD) repair after cardiopulmonary resuscitation $(C P R)$, distributed by duration of CPR. Outcomes of AAAD repair after CPR by duration of CPR. There was no survivor without any neurological complications after CPR of more than 15 minutes.

the time of onset to the operation room fell from $6.9 \pm 11.6$ hours between 2004 and 2016 to $3.8 \pm 3.1$ hours between 2017 and $2018(P=.0097)$, and time from hospital arrival to the operating room decreased from $50.6 \pm 39.1$ minutes between 2004 and 2016 to $37.7 \pm 26.4$ minutes between 2017 and $2018(P=.029)$. This situation allowed us to investigate the limitations of our efforts to save patients with AAAD undergoing CPR.

TABLE 4. Univariate and multivariate analyses of in-hospital mortality

\begin{tabular}{|c|c|c|c|}
\hline \multirow[b]{2}{*}{ Variable } & \multirow{2}{*}{$\begin{array}{c}\text { Univariable } \\
P \\
\text { value }\end{array}$} & \multicolumn{2}{|r|}{ Multivariable } \\
\hline & & $\begin{array}{c}P \\
\text { value }\end{array}$ & $\begin{array}{c}\text { Hazard ratio } \\
(95 \% \text { confidence } \\
\text { interval })\end{array}$ \\
\hline Age $>75$ y & .89 & & \\
\hline Male gender & .69 & & \\
\hline OHCA & .38 & & \\
\hline \multicolumn{4}{|l|}{ Reasons for CPR } \\
\hline $\begin{array}{l}\text { Aortic rupture or cardiac } \\
\text { tamponade }\end{array}$ & .98 & & \\
\hline Coronary malperfusion & .76 & & \\
\hline Aortic valve regurgitation & .86 & & \\
\hline Duration of CPR $>15$ min & $<.001$ & .0040 & $8.27(1.33-32.4)$ \\
\hline Ongoing CPR & .025 & .19 & $1.70(0.81-4.35)$ \\
\hline No ROSC after pericardiotomy & .034 & .054 & $3.69(0.94-8.84)$ \\
\hline
\end{tabular}

OHCA, Out-of-hospital cardiac arrest; $C P R$, cardiopulmonary resuscitation; $R O S C$, return of spontaneous circulation.
Preoperative CPR has been identified as a significant risk factor for operative death in several studies from highly experienced centers. ${ }^{3-9,15,16}$ Lee and colleagues ${ }^{15}$ reported from the Society of Thoracic Surgeons Adult Cardiac Surgery Database that CPR was required in 156 of 2982 patients with AAAD (5.2\%) and was identified as an independent predictor of death. In the International Registry of Acute Aortic Dissection, CPR was required in 126 cases $(5.9 \%)$, and $52.4 \%$ of preoperatively resuscitated patients eventually died within 30 days postoperatively; this factor thus had the greatest influence on early mortality. CPR has also been described by Goda and colleagues ${ }^{16}$ as a significant risk factor for in-hospital mortality after AAAD repair. Similar to other reports, CPR was required in the current analysis for 34 patients $(6.6 \%)$, with an overall in-hospital mortality rate of $61.4 \%$; the in-hospital mortality rate was $50.0 \%$ following OHCA and $72.2 \%$ with IHCA. The likelihood that some patients died at the primary hospital and could not be transferred to our hospital would have influenced the mortality rates.

In the present study, the only risk factor for in-hospital death was duration of CPR exceeding 15 minutes. The influence of the duration of resuscitation on clinical outcomes has been reported previously. ${ }^{17-19}$ Ballew and colleagues ${ }^{18}$ demonstrated that, in their series of 313 patients, the percentage of survivors was $45 \%$ when resuscitation duration lasted $<5$ minutes, and $<5 \%$ for resuscitation extending beyond 20 minutes. Another study reported only a $2 \%$ survival rate if resuscitation was continued beyond $10 \mathrm{mi}-$ nutes. ${ }^{19}$ In the current study, duration of CPR was shorter in survivors than in nonsurvivors, and CPR duration exceeding 15 minutes was the strongest risk factor for inhospital mortality. Reducing the duration of CPR for patients with OHCA might be difficult even with prehospital medicine. Greater effort should therefore be put into reducing the duration of CPR in patients with IHCA. Because CPR is not effective for patients with aortic rupture or cardiac tamponade even after diagnosis of AAAD, the interval from onset to emergency surgery should be shortened. Despite the relatively short interval from arrival to operating room in our hospital, improvement is still required in the emergency medical system. Every effort should be made, but CPR duration of 15 minutes may be a cutoff to save patients undergoing CPR before AAAD repair.

Three patients with OHCA and 1 patient with IHCA achieved ROSC after ECMO support. All of these patients were first diagnosed with acute coronary syndrome. One patient underwent successful percutaneous coronary intervention before AAAD repair and the other patients were rushed to an operating room for central AAAD repair with ROSC. However, only 1 patient who had preoperative coronary intervention survived AAAD repair; therefore, prompt 


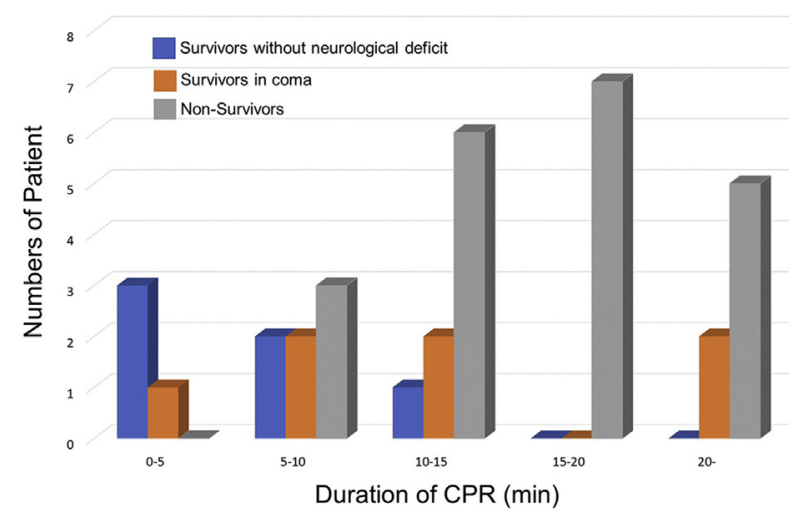

VIDEO 1. Dr Kyokun Uehara discussing the essence of our study on the outcomes of acute type A aortic dissection repair in patients who required cardiopulmonary resuscitation before surgery. Video available at: https:// www.jtcvs.org/article/S0022-5223(20)30005-2/fulltext.

recanalization of occluded coronary arteries is desirable, although it may be complicated.

More nonsurvivors required postoperative ECMO support because of severe coagulopathy, bleeding, and poor ventricular function $(P<.001)$. This might be related to the longer cardiopulmonary bypass time in the nonsurvivors. IABP was inserted because of poor ventricular function in 9 patients $(26.5 \%)$. The use of IABP is considered contraindicated because there are some possibilities of aortic rupture or extension of the residual aortic dissection. ${ }^{20}$ In our experience, there was no aortic event related to the use of IABP; we therefore consider that IABP support was effective for patients with unstable hemodynamic parameters, although careful transesophageal echocardiography should ensure that the balloon is placed in the true lumen. In the present study, no patients had aortic events caused by IABP.

Anoxic brain injury is a major cause of mortality, accounting for $68 \%$ of deaths in OHCA patients and $23 \%$ of deaths after IHCA. ${ }^{21}$ Lawton and colleagues ${ }^{22}$ showed that 11 of 282 AAAD patients $(3.9 \%)$ underwent CPR before or on arrival in the operating room. Six of those patients had early mortality after AAAD repair, and the remaining 5 survived for a range of 2.4 to 8.4 years. However, details at discharge were unclear. The current study focused particularly on those patients who underwent preoperative CPR. Although 13 patients $(38.2 \%)$ survived emergency AAAD repair in the present study, only 4 $(11.7 \%)$ were discharged home without any neurological deficits, and all of those had achieved ROSC before AAAD repair. Two patients $(15.4 \%)$ who were transferred to rehabilitation hospitals underwent ongoing CPR because of aortic rupture. Both patients achieved ROSC after pericardiotomy within 10 minutes and they recovered without any neurological deficits. On the other hand, 7 of the 14 patients who underwent AAAD repair (50\%) with ongoing CPR were unable to achieve ROSC after pericardiotomy. Only 1 of those patients survived AAAD repair, but that patient remained in a coma because of severe hypoxic brain injury. Although we can perform AAAD repair even in patients who could not achieve ROSC after pericardiotomy, we should reconsider pursuing AAAD repair for patients with such a serious condition.

Our study has several limitations. First, the study was a single-center retrospective analysis involving a small number of patients. Second, in patients with OHCA, the interval between cardiac arrest and initiation of CPR was not clearly analyzed. Similarly, details of bystander CPR were not obtained from all patients with OHCA. Third, because the aortic team at our institution can start AAAD repair as soon as their patients arrive at the hospital, the surgical results might be different from those of other hospitals.

\section{CONCLUSIONS}

In patients undergoing CPR before AAAD repair, CPR duration exceeding 15 minutes may be a contraindication for AAAD repair. We should reconsider the surgical indications for patients who do not achieve ROSC after pericardiotomy (Video 1).

\section{Webcast}

You can watch a Webcast of this AATS meeting presentation by going to: https://aats.blob.core.windows.net/media/ 19\%20AM/Sunday_May5/206F/206F/S43\%20-\%20Rap id $\% 20$ Fire $\% 20$ Abstracts $\%$ 20III/S43_12_webcast_0852 39903.mp4.

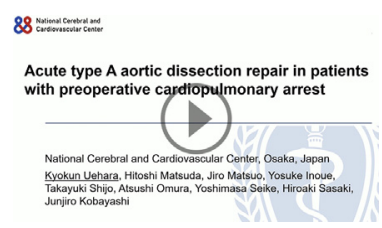

\section{Conflict of Interest Statement}

Authors have nothing to disclose with regard to commercial support.

\section{References}

1. Trimarchi S, Nienaber CA, Rampoldi V, Myrmel T, Suzuki T, Mehta RH, et al. Contemporary results of surgery in acute type-A aortic dissection: the International Registry of Acute Aortic Dissection experience. J Thorac Cardiovasc Surg. 2005;129:112-22.

2. Jussli-Melchers J, Panholzer B, Friedrich C, Broch O, Renner J, Schöttler J, et al. Long-term outcome and quality of life following emergency surgery for acute aortic dissection type A: a comparison between young and elderly adults. Eur J Cardiothorac Surg. 2017;51:465-71.

3. Apaydin AZ, Buket S, Posacioglu H, Islamoglu F, Calkavur T, Yagdi T, et al. Perioperative risk factors for mortality in patients with acute type A aortic dissection. Ann Thorac Surg. 2002;74:2034-9.

4. Hata M, Shiono M, Inoue T, Sezai A, Niino T, Funahashi M, et al. Preoperative cardiopulmonary resuscitation is the only predictor for operative mortality of 
type A acute aortic dissection: a recent 8-year experience. Ann Thorac Cardiovasc Surg. 2004;10:101-5.

5. Matsushita A, Tabata M, Fukui T, Sato Y, Matsuyama S, Shimokawa T, et al. Outcomes of contemporary emergency open surgery for type A acute aortic dissections in elderly patients. J Thorac Cardiovasc Surg. 2014;147:290-4.

6. Centofanti P, Flocco R, Ceresa F, Attisani M, La Torre M, Weltert L, et al. Is surgery always mandatory for type-A aortic dissection? Ann Thorac Surg. 2006;82: 1658-63.

7. Rampoldi V, Trimarchi S, Eagle KA, Nienaber CA, Oh JK, Bosson E, et al. Simple risk models to predict surgical mortality in acute type-A aortic dissection: the International Registry of Acute Aortic Dissection score. Ann Thorac Surg. 2007; 83:55-61.

8. Inoue Y, Minatoya K, Oda T, Itonaga T, Seike Y, Tanaka H, et al. Surgical outcomes for acute type $\mathrm{A}$ aortic dissection with aggressive primary entry resection. Eur J Cardiothorac Surg. 2016;50:567-73.

9. Evangelista A, Isselbacher EM, Bossone E, Gleason TG, Eusanio MD, Sechtem U, et al. Insights From the International Registry of Acute Aortic Dissection: a 20-year experience of collaborative clinical research. Circulation. 2018;137:1846-60.

10. Russo CF, Mariscalco G, Colli A, Santè P, Nicolini F, Miceli A, et al. Italian multicentre study on type A acute aortic dissection: a 33-year follow-up. Eur J Cardiothorac Surg. 2016;49:125-31.

11. Conway BD, Stamou SC, Kouchoukos NT, Lobdell KW, Khabbaz KR, Murphy E, et al. Improved clinical outcomes and survival following repair of acute type A aortic dissection in the current era. Interact Cardiovasc Thorac Surg. 2014;19:971-6.

12. Chikwe J, Cavallaro P, Itagaki S, Seigerman M, Diluozzo G, Adams DH. National outcomes in acute aortic dissection: influence of surgeon and institutional volume on operative mortality. Ann Thorac Surg. 2013;95:1563-9.

13. Conzelmann LO, Weigang E, Mehlhorn U, Abugameh A, Hoffmann I, Blettner M, et al. Mortality in patients with acute aortic dissection type A: analysis of pre- and intraoperative risk factors from the German Registry for Acute Aortic Dissection Type A (GERAADA). Eur J Cardiothorac Surg. 2016;49:e44-52.

14. Committee for Scientific Affairs, The Japanese Association for Thoracic Surgery. Thoracic and cardiovascular surgery in Japan during 2015: annual report by The
Japanese Association for Thoracic Surgery. Gen Thorac Cardiovasc Surg. 2018; 66:581-615.

15. Lee TC, Kon Z, Cheema FH, Grau-Sepulveda MV, Englum B, Kim S, et al. Contemporary management and outcomes of acute type A aortic dissection: an analysis of the STS Adult Cardiac Surgery Database. J Card Surg. 2018; 33:7-18.

16. Goda M, Imoto K, Suzuki S, Uchida K, Yanagi H, Yasuda S, et al. Risk analysis for hospital mortality in patients with acute type A aortic dissection. Ann Thorac Surg. 2010;90:1246-50.

17. Goldberger ZD, Chan PS, Berg RA, Kronick SL, Cooke CR, Lu M, et al. Duration of resuscitation efforts and subsequent survival after in-hospital cardiac arrest. Lancet. 2012;380:1473-81.

18. Ballew KA, Philbrick JT, Caven DE, Schorling JB. Predictors of survival following in-hospital cardiopulmonary resuscitation. A moving target. Arch Intern Med. 1994;154:2426-32.

19. Schultz SC, Cullinane DC, Pasquale MD, Magnant C, Evans SR. Predicting in hospital mortality during cardiopulmonary resuscitation. Resuscitation. 1996; 33:13-7.

20. Jaussaud N, Durand M, Boignard A, Porcu P, Hacini R, Blin D, et al. Is intraaortic balloon pump absolutely contraindicated in type A aortic dissection? $J$ Cardiovasc Surg. 2015;56:513-8.

21. Laver S, Farrow C, Turner D, Nolan J. Mode of death after admission to an intensive care unit following cardiac arrest. Intensive Care Med. 2004;30: 2126-8.

22. Lawton JS, Moon MR, Liu J, Koerner DJ, Kulshrestha K, Damiano RJ Jr, et al. The profound impact of combined severe acidosis and malperfusion on operative mortality in the surgical treatment of type A aortic dissection. J Thorac Cardiovasc Surg. 2018;155:897-904.

Key Words: acute type A aortic dissection, cardiopulmonary resuscitation, out-of-hospital cardiac arrest, in-hospital cardiac arrest, return of spontaneous circulation 